\title{
Case Presentation: Giant Fibroadenoma
}

\section{Tamayo Carbon AM, Vila Garcia E*, Gaitan Garcia CA, Alatorre Aguirre CA and Bencosme Escarraman YY}

Surgical Hospital Hermanos Ameijeiras, Cuba

*Corresponding author: Eyleen Vila Garcia, Assistant Professor, Services of Plastic Surgery and Caumatology and General Surgery, Surgical Hospital Hermanos Ameijeiras, Havana City, Cuba, Tel: 53232327; Email: hielenvg@infomed.sld.cu

\section{Case Report \\ Volume 4 Issue 1}

Received Date: January 08, 2020

Published Date: February 14, 2020

DOI: $10.23880 /$ ijtps-16000139

\section{Abstract}

Fibroadenomas are benign lesions of the breast, very frequent, composed of glandular and stromal tissue. They are more frequent in women from 20 to 39 years of age, although they can appear in women of any age. It is considered as a giant fibroadenoma if it reaches a size greater than $5 \mathrm{~cm}$ or a weight greater than $500 \mathrm{gr}$.

We analyze a case of a 36-year-old female patient who comes to the clinic for presenting breast asymmetry at the expense of an enlarged left breast; Trucut biopsy is performed, reporting lipoma, so breast reconstruction is performed with stents. The transoperative finding was a giant tumor, performing its exeresis. The histological result reports breast fibroadenoma with foci of hyalinization and foci of fatty infiltration. It can be affirmed that breast pathology should always be studied in detail to establish the correct diagnosis.

Keywords: Fibroadenoma; Benign Tumors; Breast Tumors

\section{Introduction}

Breast asymmetry is one of the most frequent reasons for consultation in plastic surgery. The difference can be in shape, size, position and projection. When the difference in volume exceeds $100 \mathrm{cc}$ it is called anisomastia.

Benign breast pathology includes: tumors, trauma, abscesses, mastitis, cysts, among others. The diagnosis should be as early as possible, as well as its treatment because certain benign diseases have increased the risk of malignancy.

Benign breast tumors have an incidence of $86.69 \%$. Of these, the fibroadenoma is the most common, representing $85 \%$ of cases. The Fibroadenoma is a common benign breast lesión [1-3], which typically occurs in young patients between the ages of 20 and 35 [4]. The most frequent clinical presentation is the presence of a palpable nodule or mass, followed by pain as a second symptom. About $5-10 \%$ of these masses or nodules are diagnosed as malignant tumors, within which infiltrating ductal carcinoma is the most common.

Fibroadenoma is usually small and can be treated conservatively; Only between 0.5 and $2 \%$ of these lesions will grow rapidly. Giant fibroadenomas, larger than $5 \mathrm{~cm}$ or greater than 500 gr [1-5], are associated with significant deformities and increased suspicion of malignancy, which is why they usually require surgical treatment [1]. The diagnosis is made exclusively by biopsy, although it is previously suspected by the clinic and by images. You should always rule out virgin breast hypertrophy and the Phylodes tumor that have similar behaviors but different treatments. 


\section{International Journal of Transplantation \& Plastic Surgery}

\section{Case Report}

A 36-year-old female patient who attended the consultation due to the increase in size and asymmetry of the left breast that began in her teens. He has a personal history of bronchial asthma, without medication, allergy to penicillin and azithromycin. On physical examination, asymmetry of the breasts is observed at the expense of enlargement of the left, low implantation, wide base, upper empty pole on the right side, descending below the submammary groove $3 \mathrm{~cm}$, nipple areola complex without alterations (Figure 1).

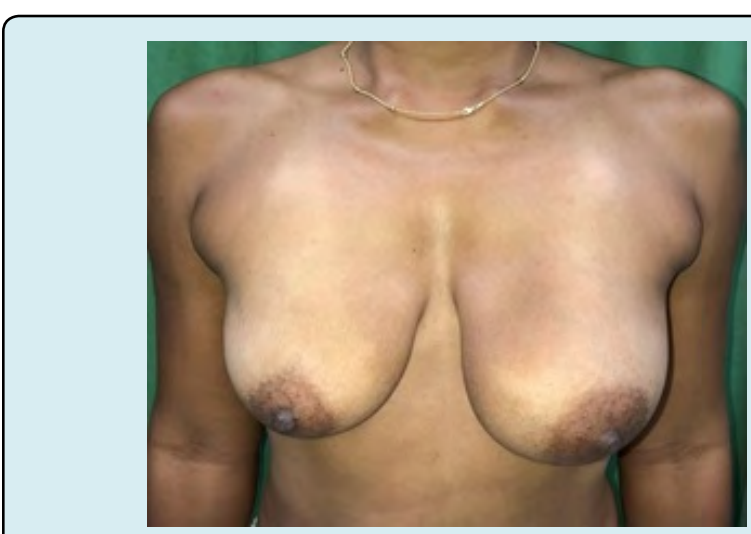

Figure 1: Asymmetry of the left breast.

In the left breast, a tumor of approximately $4 \times 9 \mathrm{~cm}$ is palpated, with smooth surface, regular edges, not painful and movable.

Breast ultrasound and trucut biopsy are performed that report adipose tissue suggestive of lipoma (Figure 2).

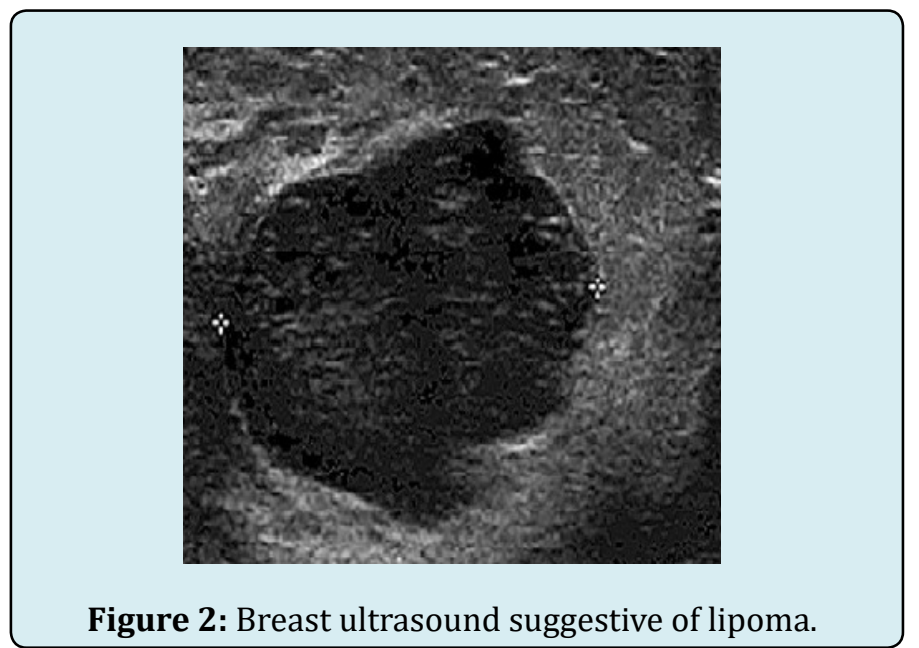

Given the situation described, the excision of the lipoma and remodeling of the breast tissue with the placement of silicone stents for correction of asymmetry is decided. The transoperative findings were: left breast tumor, well delimited, lobed, $15 \mathrm{~cm}$ in diameter, with a weight of $850 \mathrm{gr}$ (Figure 3).

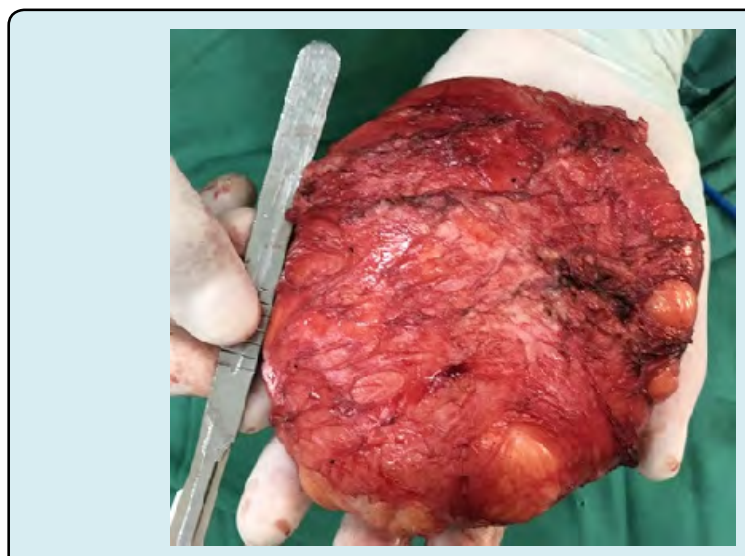

Figure 3: The transoperative findings.

The histopathological report was a tumor with foci of hyalinization and fatty infiltration, consisting of stroma, dense collagen and epithelium without atypia or evidence of malignancy (Figure 4).

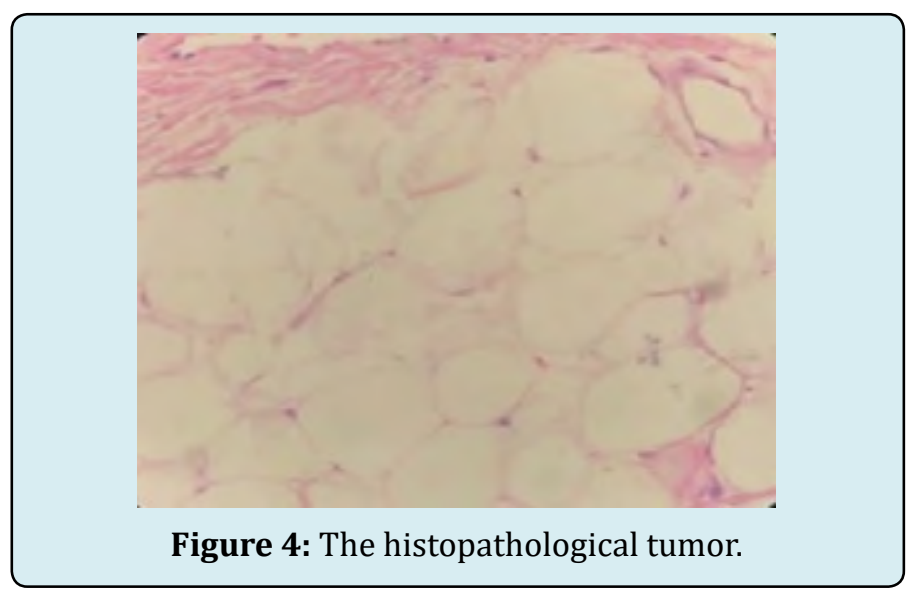

The patient evolved without complications and the immediate postoperative period was satisfactory in terms of symmetry, scarring and aesthetic results (Figure 5).

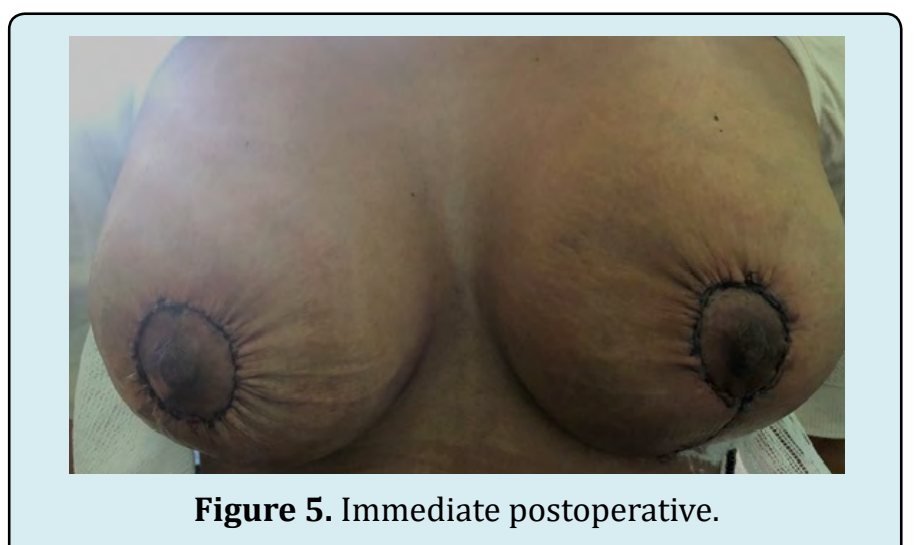




\section{International Journal of Transplantation \& Plastic Surgery}

\section{Discussion}

Benign breast tumors are common, with giant fibroadenomas being the most common cause of unilateral breast asymmetry in women between the ages of 20 and 35 [6]. The cause of these large masses is unknown. Hormones can play an important role, because these lesions occur frequently in puberty, pregnancy and with oral contraceptives [7]. Although they are benign, giant fibroadenomas can compress surrounding tissue and alter the lobular structure by increasing size and vascularization; due to the rapid growth of an encapsulated tumor [8]. Fibroadenoma is a painless, solitary and unilateral growth mass, with no evidence of infection and can double in size in 3 to 6 months to reach $20 \mathrm{~cm}$ in diameter, which distorts the shape of the breasts In addition, when they are complex fibroadenomas they can have histological changes such as cysts, calcifications and apocrine changes that can increase the risk of developing breast cáncer [9]. Superficial manifestations of giant fibroadenomas can be similar to malignant processes such as: ulceration and inversion of the nipple [10]. Early detection, diagnosis and treatment of fibroadenomas should be performed early to minimize the risk of complications. The diagnosis of fibroadenomas is made with detailed physical examination, breast ultrasound and trucut biopsy or fine needle aspiration [11]. It should always be distinguished from phylodes tumor and virginal hypertrophy. The phylodes tumor is a fibroepithelial tumor that accounts for $0.3-0.9 \%$ of mammary neoplasms and, although it usually appears after the fourth decade, in $8 \%$ of cases it develops in women under 20 years of age. old. The histological characteristics that differentiate it from fibroadenomas are not well defined, which causes differential diagnosis to be very difficult on many occasions, taking into account that its clinical and ultrasound behavior can be very similar. Virginal hypertrophy, also called juvenile gigantomastia, is a rare benign condition that causes excessive and diffuse growth of one or both breasts whose clinical, ultrasound and histological diagnosis is very similar to that of Fibroadenoma [12].

In the presented patient, a preoperative trucut biopsy was performed, which reported adipose tissue, so that surgical treatment for asymmetry correction was decided, with the transoperative finding of the tumor described above.

Even though in most cases the tumor is palpable and well defined, there is a possibility that it may be presented as a transoperative finding. The patient presented had no family history of nodules or breast cancer and had a giant fibroadenoma in a short period of time. The excision of the tumor and breast reconstruction with stents were performed in a single surgical time and symmetry was achieved from the immediate postoperative period. The patient should have adequate follow-up in search of future breast masses.

The reported case had as its main symptom the increase in volume of the breast with rapid growth, which can be alarming for women. Although the patient's priority is to improve her body's self-image, the plastic surgeon must focus not only on the challenge of obtaining a good aesthetic result but also on the correct diagnosis to maintain and raise the patient's biopsychosocial well-being status and quality of life.

For all the above, we conclude that giant fibroadenoma is a cause of breast asymmetry in young patients.

It is recommend the application of the Breast Cancer Early Detection Program (effective in Cuba since 1989) for all women, which includes: breast self-examination for all women, annual Mastology consultation for those over 30 years of age and mammography for those over 40 years and more; to ensure early detection and proper treatment of breast diseases.

\section{References}

1. Kalim M, Ahmad S, Ozair F (2018) Frequency of fibroadenoma in patients presenting with breast lump. J Postgrad Med Inst 32 (1): 95-98.

2. Guzman M, Heron S, Ramos $P$ (2011) Giant breast Fibroadenoma. Clin Invest Gin Obst 38(1): 32-34.

3. Hidalgo J, Aznar I, Fernandez A 2011) Recurrent juvenile giant fibroadenoma mastectomy. Prog Obstet Ginecol 54(10): 528-531.

4. Corredor B, Marquez M, Lobo F (2011) Giant breast fibroadenoma in adolescents: diagnostic-therapeutic procedures. Clin Invest Gin Obst 38(1): 48-54.

5. De la Garza 0, Days V, Paz M (2018) Giant juvenile fibroadenoma: case report. Ginecol Obstet Mex 86(9): 616-620.

6. Jayasinghe Y, Simmons P (2019) Fibroadenomas in adolescence. Curr Opin Obstet Gynecol 21(5): 402-406.

7. Greydanus D, Parks D, Farrell E (2017) Breast disorders in children and adolescents. Pediatric Clin North Am 36: 601-638.

8. Park C, David L, Argent L (2006) Breast Asymmetry: Presentation of a Giant Fibroadenoma. Breast J 12(5): 451-461.

9. Matz D, Kerivan L, Reinigen M, Akman K, Lozicki A, et al. (2013) Breast Preservation in women with giant juvenile 


\section{International Journal of Transplantation \& Plastic Surgery}

Fibroadenoma. Clin Breast Cancer 13(3): 219-222.

10. Ter R, Bruce S, Nahabedian M (2017) Partial Breast Reconstruction with Goldilocks Technique after excision of giant fibroadenoma: a case report. Plast Reconstr Surg Glob Open 5(1): e1200.

11. Qu S, Zhang W, Zhang Q, Zhang J, Lu R, et al. (2019) The vacuum-assisted breast biopsy system is an effective treatment strategy for breast lumps after augmentation with autologous fat grafting. Aesthetic Plast Surg 43(5): 1152-1157.

12. Zaldívar J (2011) Virginal mammary hypertrophy in an adolescent. MEDISAN 15(9).

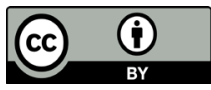

